\title{
IRRIGAÇÃO POR GOTEJO EM MORANGO *
}

\author{
Antonio Fernando Olitta \\ Keico Minami
}

\section{INTRODUÇAO}

0 método de irrigação por gotejo foi desenvolvido em termos de uma agricultura intensiva e altamente produtiva, onde as melhores técnicas agronômicas são empregadas para assegurar a máxima produção. Um dos principais objetivos ao se adotar este método numa determinada cultura, é que esta proporcione um alto rendimento por unidade de área de modo a compensar o capital empregado na aquisição do equipamento. A cultura do morango apresenta-se como uma das mais promissoras em termos de lucro líquido, sendo perfeitamente adaptada aos efeitos especiais de umidade do solo que este método de irrigação proporciona.

A superioridade do gotejamento na cultura do morango foi salientada por BOAZ (1970) num trabalho de comparação com outros métodos de irrigação. VOTH (1970) trabalhando com canteiros de fila dupla e usando um espaçamento nos gotejadores de $60 \mathrm{~cm}$ na lateral, encontrou os seguintes resultados numa comparação com o método de irrigação por sulco.

\begin{tabular}{lcccc}
$\begin{array}{l}\text { Método de } \\
\text { Irrigação }\end{array}$ & $\begin{array}{c}\text { Acre-feet } \\
\text { de água }\end{array}$ & $\begin{array}{c}\text { Produção em } \\
\text { Março-Abril }\end{array}$ & $\begin{array}{c}\text { gramas/planta } \\
\text { Maio-Junho }\end{array}$ & $\begin{array}{c}\text { Tamanho } \\
\text { do Fruto }\end{array}$ \\
\hline Sulco & 2,20 & 246 & 131 & 14,8 \\
Gotejo & 0,95 & 244 & 188 & 15,6 \\
\hline
\end{tabular}

Outro experimento foi realizado por VOTH (1972) para avaliar diferentes modos de posicionar os gotejadores, forma de canteiro e concentrações de planta por área de modo a se obter uma maior produção na cultura do morango. Os resultados mostram novamente uma maior economia da água de irrigação quando comparada com a irrigação por sulcos.

- Entregue para publicação em 31/12/1974. Trabalho subvencionado pela Fundação de Amparo a Pesquisa do Estado de São Paulo (FAPESP) e CIPLA - Cia. Industrial de Plásticos.

* Prof. Assist. Dr. do Depto de Engenharia Rural da ESALQ/USP.

*** Prof. Assist. do Depto de Agricultura e Horticultura da ESALQ/USP. 
O presente experimento foi conduzido para avaliar o método de irrigação por gotejo em nossas condições relacionando ao método tradicional de sulcos, além de uma comparação de diferentes frequências de irrigação, com o fim de se obter um manejo ótimo deste método na cultura do morango.

\section{MATERIAL E METODO}

O experimento foi realizado no Campo Experimental do Departamento de Agricultura e Horticultura Setor de Horticultura, da E. S. A. L. Q. O clima é Cwa pela classificação de Köppen, qual seja mesotérmico umido subtropical com inverno seco. O solo foi classificado como da Série Luiz de Queiroz. A cultura do morango foi conduzida segundo as técnicas correntes, empregando-se a variedade Monte-Alegre cujas mudas foram produzidas no mesmo local. Foram estabelecidos 8 canteiros de $25 \mathrm{~m}$ de comprimento, empregando-se a cobertura com plástico preto. As plantas foram espaçadas de $30 \mathrm{~cm}$ na linha e $40 \mathrm{~cm}$ na entrelinha, com 3 linhas de planta por canteiro de $1,20 \mathrm{~m}$ de largura.

0 transplante das mudas se deu em $30 / 5 / 74$, sendo a colheita iniciada em $12 / 7$, continuando até $9 / 9$, na base de duas vezes por semana. Os frutos apresentavam-se de maduros à $2 / 3$ da maturação, sempre em tamanho comercial.

$O$ delineamento experimental constituiu-se de 4 tratamentos de modo a variar a frequência de irrigação equivalente a intervalos de 1 dia (diário), 2 dias e 3 dias na irrigação por gotejo para os tratamentos 1,2 e 3 respectivamente, e mais um tratamento 4 de irrigação por sulcos.

Os tratamentos de irrigação foram considerados para se aplicar sempre mesma quantidade de água, variando somente a frequência e o tempo de irrigação. Um dos canteiros foi utilizado para o controle com tensiômetros, a fim de se determinar um fator de transformação dos valores de evaporação de um tanque classe A localizado ao lado do experimento, em dados de consumo de água para irrigação por gotejamento.

O sistema de irrigação por gotejo constituiu-se de: um reservatório elevado de capacidade 1000 l abastecido continuamente de modo a apresentar sempre uma carga hidráulica de $4,5 \mathrm{~m}$; uma linha de derivação de de $11 / 2$ " e linhas laterais de $3 / 4$ ". Os gotejadores foram espaçados de $1.20 \mathrm{~m}$, totalizando $21 \mathrm{em}$ cada lateral. O equipamento de irrigação foi fornecido pela CIPLA - Cia. Industrial de Plásticos com sede em Joinville, SC sendo o gotejador CIPLA escolhido por suas características de regulagem de vazão, possibilitando uma alta uniformidade na irrigação. 


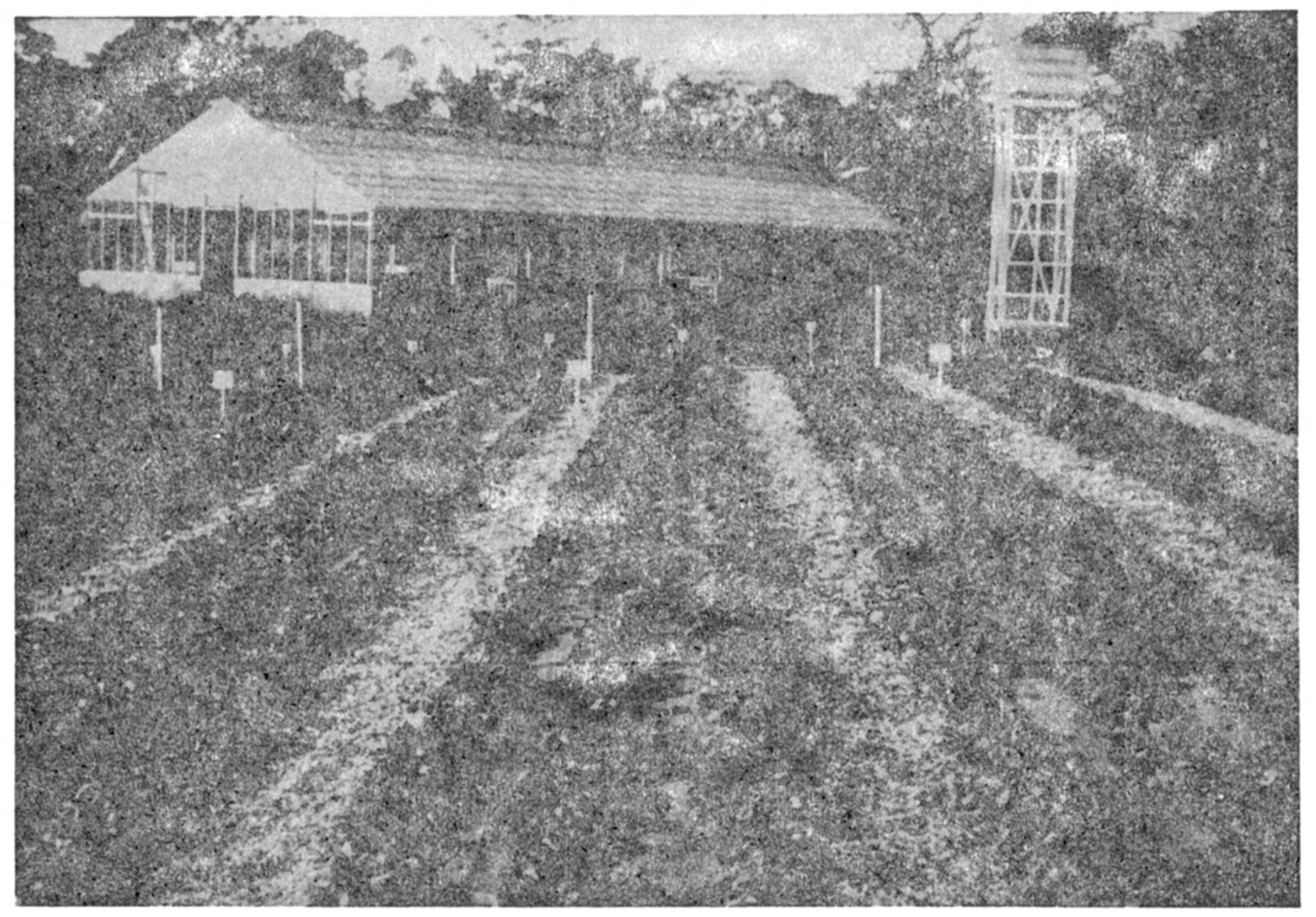

Fig. 1 - Vista geral do experimento.

A aplicação da água foi uniforme em todo o experimento inicialmente, e após o estabelecimento das plantas houve um controle semanal da irrigação, repondo cerca de $70 \%$ da água evaporada. Obteve-se a confirmação deste valor pelo controle realizado com os tensiômetros colocados a uma profundidade de $15 \mathrm{~cm}$ e distanciados de 20 e $40 \mathrm{~cm}$ do gotejador. Foram utilizados 3 pares de tensiômetros de mercúrio nesta determinação. 0 cálculo da irrigação foi feito com base nos seguintes valores:

vazão do gotejador $=2 \mathrm{lph}$

evaporação = tanque classe $\mathrm{A}$ (média semanal)

área $=1.44 \mathrm{~m}^{2}$ para 1 gotejador

fator de cobertura $\mathrm{K}=100 \%$

eficiência da irrigação $\mathrm{Ef}=90 \%$

fator de consumo de água $\mathrm{f}=70 \%$.

Adotando o procedimento descrito por HOWELL e HILER (1972), foram calculados os tempos de irrigação para os tratamentos 1,2 e 3 , apresentados no Quadro 1. 
QUADRO 1 - Tempo de irrigação em horas para valores de evaporação do tanque classe $A$.

\begin{tabular}{|c|c|c|c|}
\hline \multirow{2}{*}{$\begin{array}{c}\text { Evaporação } \\
\text { (mm/dias) }\end{array}$} & \multicolumn{3}{|c|}{ Tempo de irrigação (horas) } \\
\cline { 2 - 4 } & por dia & 2 dias & 3 dias \\
\hline 4.0 & 2.2 & 4.4 & 6.6 \\
4.5 & 2.5 & 5.0 & 7.5 \\
5.0 & 2.8 & 5.6 & 8.4 \\
5.5 & 3.1 & 6.2 & 9.3 \\
6.0 & 3.3 & 6.6 & 9.9 \\
6.5 & 3.6 & 7.2 & 10.8 \\
7.0 & 3.9 & 7.8 & 11.7 \\
\hline
\end{tabular}

A época de colheita totalizou 60 dias, não ocorrendo neste período uma precipitação significativa de modo a influir nos tratamentos de irrição da cultura.

\section{RESULTADOS E DISCUSSAO}

O efeito das variações na frequência de irrigação por gotejo pode ser avaliado pelos dados apresentados na Fig. 2, assim também, pode-se comparar as produções relativas aos métodos de gotejo e sulco. Convém salientar que a região de Piracicaba não é ideal para a cultura do morango, devido ao curto período de inverno, mas mesmo assim, as produções obtidas foram relevantes (Quadro 2). O maior interesse deste trabalho é salientar as diferenças encontradas nos tratamentos de irrigação em termos relativos ao desenvolvimento da planta (Figs. 3 e 4) e não referente a procura do valor máximo de produção.

QUADRO 2 - Resultados de Produção extrapolados para kg/ha durante o ciclo da cultura de morango.

\begin{tabular}{|l|c|c|}
\hline TRATAMENTO & PRODUÇÃO TOTAL EM Kg/ha & $\%$ \\
\hline 1 (diário) & 11.053 & 156 \\
2 (2 dias) & 12.658 & 178 \\
3 (3 dias) & 13.598 & 192 \\
4 (sulco) & 7.804 & 100 \\
\hline
\end{tabular}


Observou-se um maior desenvolvimento das plantas sob a irrigação por gotejo, efeito este salientado na produção de materia seca $\left(80^{\circ} \mathrm{C}\right)$ e também pelo número de folhas por planta. Dentro dos tratamentos de frequência de irrigação os resultados mostraram-se mais satisfatórios para um intervalo de 3 dias entre as irrigações. Isto reveste-se de grande importância no manejo da irrigação visto que o custo de operação será menor para uma irrigação menos frequente.

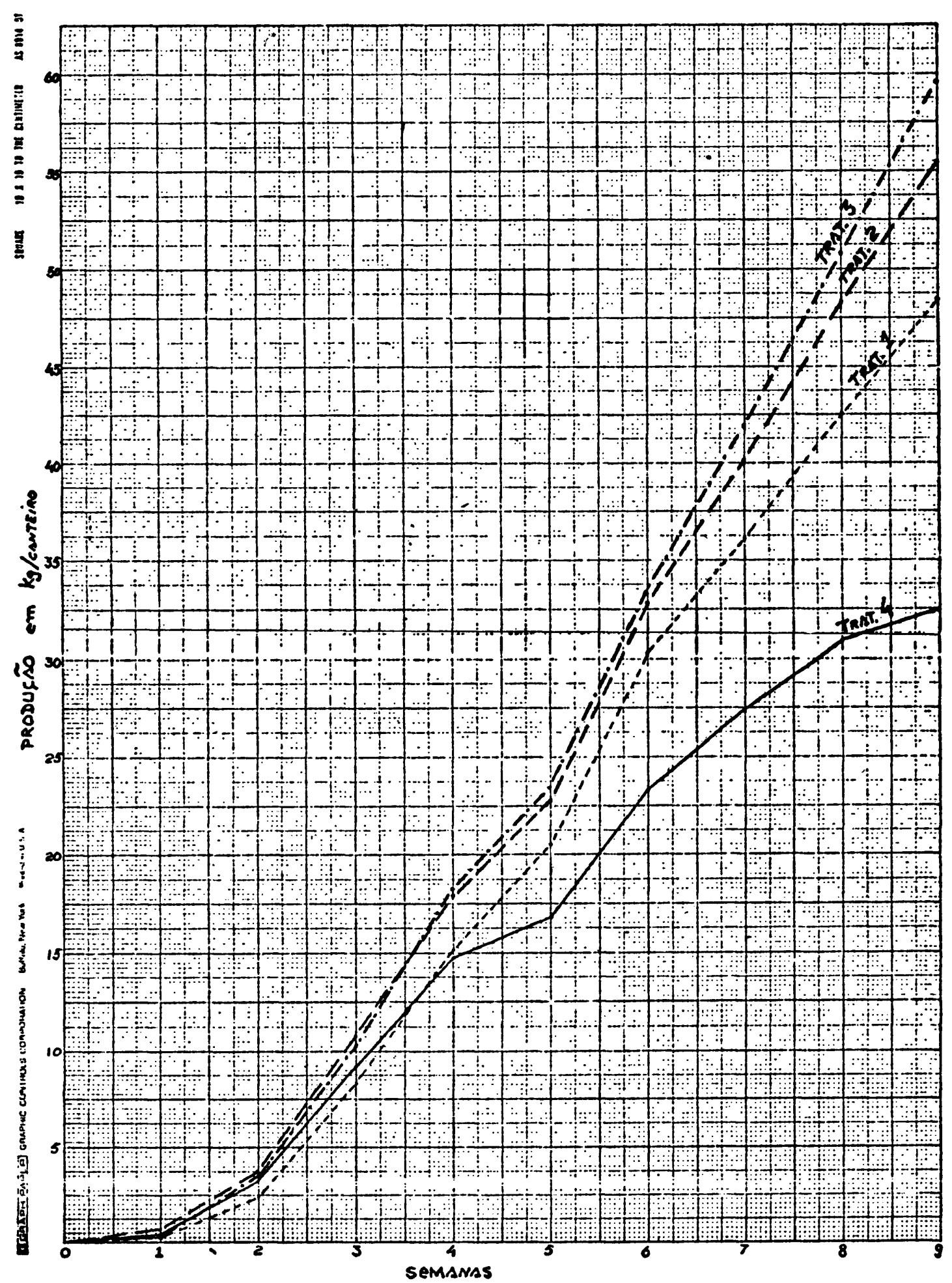

Fig. 2 - Produção acumulada semanal em $\mathrm{kg} /$ canteiro de $25 \mathrm{~m}$ de comprimento, da cultura de morango. 


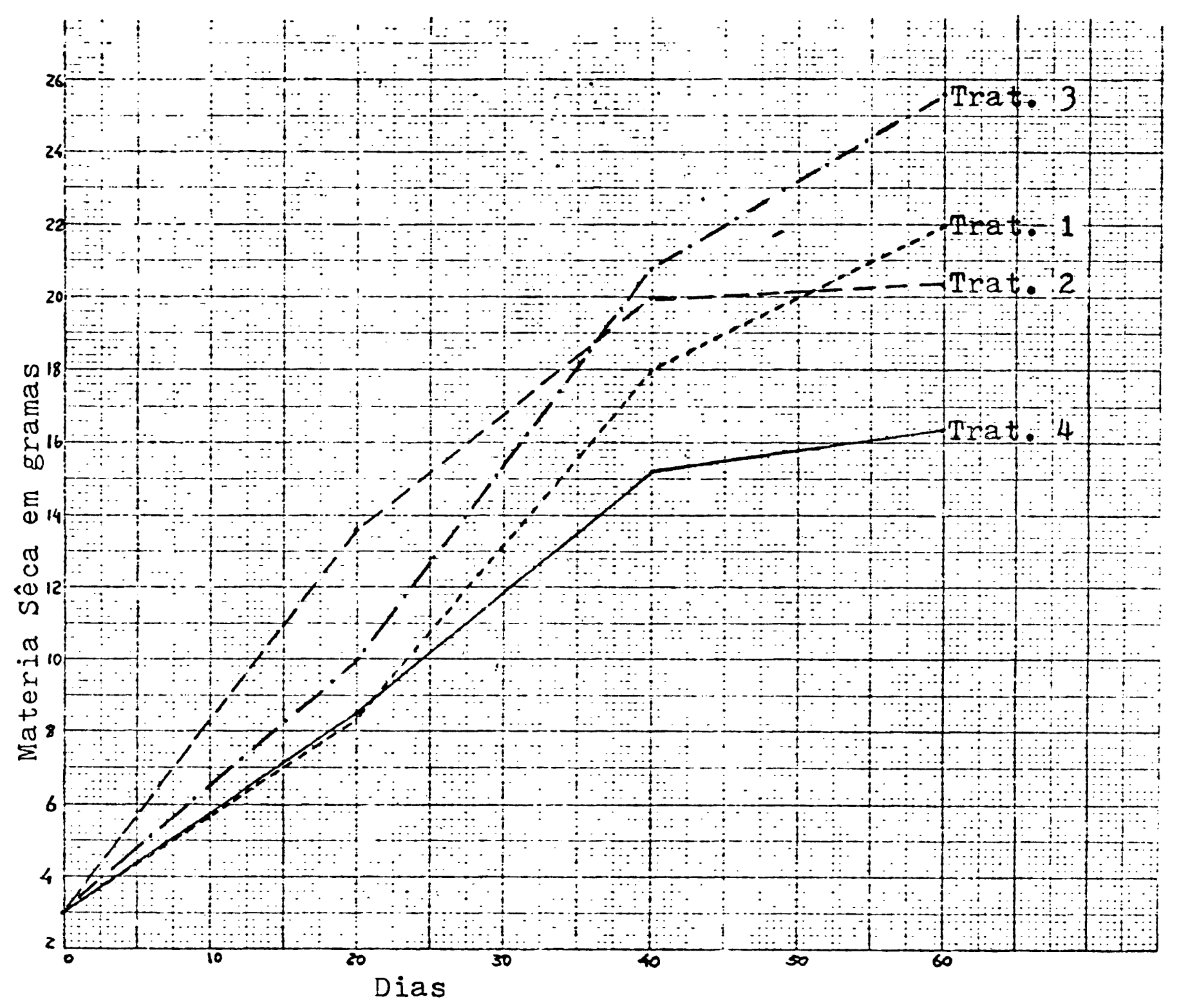

FIG. 3 - Produção de materia sêca no ciclo da cultura de morango (média de 5 plantas) 


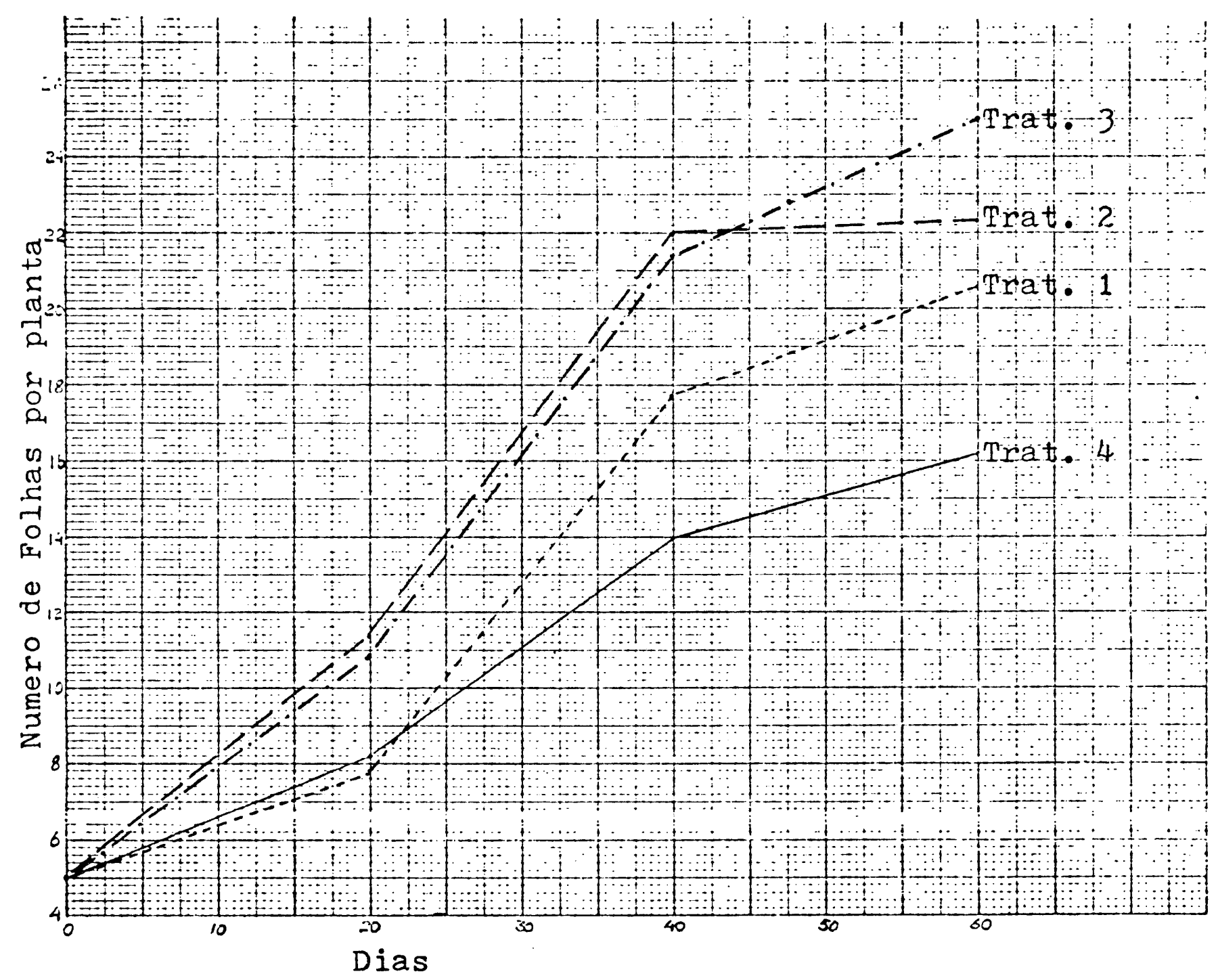

FIG. 4 - Número de folhas por planta no ciclo do morango (média de 5 plantas) 


\section{CONCLUSÓES}

A utilização de um fator de consumo $f=0.7$ em relação a evaporação do tanque classe A mostrou-se bastante adequada para a cultura de morango em nossas condições.

Os resultados de produção e desenvolvimento da planta no ciclo da cultura mostraram o melhor desempenho do método de irrigação por gotejo em relação a irrigação por sulcos, assim como, o emprego de uma frequência de irrigação equivalente a 3 dias. Isto reveste-se de importância econômica em termos de utilização do equipamento e menor gasto na mão de obra para o manejo da irrigação.

\section{LITERATURA CITADA}

BOAZ, M. 1970 - Trickle Irrigation in Israel. Israel Agriculture.

HOWELL, T. A. and E A. HILER. 1972 - Trickle Irrigation System Design. ASAE paper n.9 72-221.

VOTH, V. 1970 - Evaluation of an Experimental Strawberry Bed-Top Irrigation System. Proceedings of Drip Irrigation Seminar. Escondido, Calif. p. 17-18.

1972 - New Irrigation Method and Bed Shape of California Strawberries. Proceedings of Drip Irrigation Seminar. Escondido, Calif. p. 30-32. 